\title{
O LIVRO DO AMOR DE MARSILIO FICINO
}

Marco Lucchesi

SÍNTESE - Um dos autores mais importantes do Renascimento é o italiano Marsílio Ficino. Deixando de lado os estudos filosóficos baseados em Aristóteles e Lucrécio, voltou-se com afã a Platão. Em seu Comentário ao Banquete de Platão, ele retoma o filósofo grego e, deixando-se influenciar também pela Ética aristotélica, por Cícero, Agostinho e os poetas italianos, entre outros, produz uma obra ainda capaz de despertar admiração e surpresa no leitor contemporâneo.
ABSTRACT - The Italian Marsilius Ficinus is one of the most important authors in the Renaissance. Leaving aside the philosophical studies based on Aristotle and Lucretius, with enthusiasm he has studied Plato. In his Commentary on Plato's Symposium, he retakes the Greek philosopher and produces a work which yet causes admiration and surprise to modern readers. In his work he also was influenced by Aristotle's Ethics, by Cicero, Augustine, among others, as well as by the Italian poets.

\section{I - A coisa amada'}

O Comentário ao Banquete de Platão é ainda capaz de despertar admiração e surpresa no leitor contemporâneo. Isso porque a obra de Ficino é clara e apaixonada. E a poesia sobrepaira em todas as suas páginas. Um rasgo de entusiasmo e um rasgo de melancolia constituem o seu percurso dialético. Outras vezes, é o desespero que suprime a malha conceitual. Uma filosofia da imortalidade estruturada em duas pontas: Deus e o Amor. É o que vamos ler em seu Comentánio.

Ficino partiu do Banquete e do Fedro, dois grandes diálogos que ensinavam a relação entre o bem e a beleza, da Ética de Aristóteles e do Lélio de Cícero. A todos estes, juntou São Paulo e Santo Agostinho, que ensinavam a dimensão da caridade, bem como os poetas do dolce stil nuovo como Guinzelli e Cavalcanti. A Comédia de Dante e o Cancioneiro de Petrarca perfazem a síntese de sua filosofia do amor. Perfazem, mas não determinam. Marsilio Ficino sabe destramar a tradição e a reorganizar dentro de um sistema novo e de todo fascinante. Ultrapassa a condição de fragmentos para instaurar um discurso.

Para o filósofo, o amor humano é uma preparação para o amor divino. Tudo parte da semelhança. E quando o amor é verdadeiro os amantes se identificam um

' O estudo que segue è uma parte da conferência realizada na Universidade de Colônia, intitulada

"Die Gegenseitigkeit der Liebe bei Ficino und Camões".

\begin{tabular}{|l|l|l|l|l|l|}
\hline VERITAS & Porto Alegre & v. 42 & $\mathrm{n}^{2} 3$ & Setembro 1997 & p. 703-710 \\
\hline
\end{tabular}


com o outro. Passamos do amor solitário ao amor recíproco. Semelhança e reciprocidade fundamentam a sua estrutura:

"A semelhança gera o amor. A semelhança é uma certa natureza igual em vários. Pois se eu sou semelhante a ti, tu também és necessariamente semelhante a mim. Portanto, a mesma semelhança, que impele que eu te ame assim como tu me amas, obriga-te também a me amares."

Algo parecido com o poema de Camões: o amador se transforma na coisa amada e em si mesmo possui a parte desejada. Lemos no Comentário que

"na verdade cada um tem a si próprio e ao outro. Pois este existe naquele. E aquele existe, mas neste. Com efeito, enquanto eu te amo, eu me encontro amante, em ti, estando eu a pensar em mim, e recobro-me por mim mesmo, perdido na minha negligência, conservando-me em ti. A mesma coisa fazes em mim."

E prossegue:

"Pois eu, depois que perdi a mim mesmo, se por ti me recobro, por ti tenho a mim; se por ti tenho a mim, eu te tenho antes e mais que a mim mesmo, e estou mais próximo de ti que de mim, visto que me ligo a mim precisamente por ti."

Tndavia, apesar dessa profunda união, os amantes não sabem exatamente o que buscam um no outro. Querem sempre mais e já não sabem o que significa esse mais. Sentem uma nostalgia arraigada, mas não sabem determinar a sua extensão. Sofrem quando amam e desconhecem por que sofrem. Têm saudade do imponderável. A semelhança e a reciprocidade não resolvem esse mistério divino. Primeiro, porque a sede de quem ama não se aplaca ao ver ou ao tocar o corpo do amado. Não deseja este ou aquele corpo, mas o resplendor divino infuso no outro. A presença de Deus é como um suave perfume que faz pressentir o sabor de um fruto ignorado. Igualmente, o temor e a reverência do amante ao ver o amado é um temor inconsciente em face de Deus.

Tais argumentos demonstram que o amor não se limita a duas pessoas, mas a três: dois seres humanos e um Deus: o amante e o amado são como espelhos que guardam a imagem imperfeita do Pai. É isso que os aproxima um do outro. Precisam compreender a profundidade desse Bem. Pois amar é voltar à Origem. Vejamos.

\section{II - Motivos de inquietação}

Num conhecido diálogo de Platão, o desejo da filosofia é o desejo da morte. Inicialmente terríveis, as palavras de Sócrates ganham maior clareza à medida que avançamos na leitura do Fédon. Filosofar é libertar-se do corpo para se ocupar da alma, é ir deixando morrer as solicitações do corpo na realidade do pensamento. Ao nosso redor, apenas miragens e simulacros. Tudo mergulhado em sombras. E o corpo sendo uma extensão dessa realidade. Se buscamos o conhecimento puro, devemos examinar as coisas com a alma. Passar da esfera do sensivel para a esfera do inteligivel. A nossa pátria é a altíssima região da qual baixamos a este mundo terreno, lá onde mora o nosso Pai. Por isso é preciso morrer. Porque habitamos a Distância. Porque vivemos no Exílio. Transcender: eis a palavra-chave na concepção platônica. Morte e transcendência preparam o fim da Distância e o 
regresso ao seio da Unidade. A nostalgia de Deus é a ante-câmara da morte. Eis o que pensava justamente Marsilio Ficino. Filosofar é morrer.

Ficino é um ser enamorado e atormentado por Deus. E as suas páginas dão o testemunho dessa procura incessante do Significado. Da imagem e do rosto de Deus. A filosofia para Ficino não é senão amor a Deus e regresso a Deus. Voltar ao Princípio dos princípios e contemplar a Causa das causas. Passar da superfície ao Profundo. Pois o homem - sem Deus - é uma devastadora inquietação. O horizonte puramente físico de Aristóteles e Lucrécio jamais serviu de consolo para Ficino." Só fez aumentar-lhe a busca do Sentido. O maior desejo do homem - lembra 0 filósofo - consiste em tornar-se onipotente. Ele mede o céu, a terra e os abismos. O céu não lhe parece tão alto. $O$ centro da Terra, tão profundo. E 0 abismo já não the causa mais terror. As distâncias espaciais e temporais não 0 impedem de chegar aonde bem entende. Contudo, a inquietação e a melancolia não se despegam de sua alma. Não lhe basta a conquista da Terra. Sente-se acabrunhado pela vanidade das coisas. Precisa do Outro. Tem saudades do Infinito. E não quer sucumbir nas ondas do tempo.

$\mathrm{O}$ endereço do homem é outro. Assim como o Sol atrai as flores, a Lua move as águas, e Marte comanda os ventos, também sofremos o impacto da beleza, que é o rosto de Deus, e que atrai a alma (a sé tira) por uma lei de intrínseca semelhança. Estas páginas de alta poesia - que sabem unir metáforas e conceitos, símbolos e alegorias ${ }^{3}$ fazem da filosofia de Ficino um pensamento emocionado. Comprometido com Deus e com a imortalidade da alma. Diz Lourenço, o Magnífi$\mathrm{CO}$ :

Della divina infinità l'abisso

quasi per una nebbia contempliamo, benché l'alma vi tenga l'occhio fisso;

Tanto Kristeller como Garin mostraram brilhantemente como a renúncia de Ficino aos estudos da juventude (Lucrécio e Aristóteles) repercutem na Theologia Platonica. Penso no De rerum natura:

Sic igitur solem, lunam, stellasque putandum

ex alio atque alio lucem iactare subortu, et primum quid flammarum perdere semper; inviolabilia haec ne credas forte vigere.

Denique non lapides quoque vinci cernis ab aevo, non altas turris ruere et putrescere saxa, non delubra deum simulacraque fessa fatisci, nec sanctum numen fati protollere finis posse neque adversus naturae foedera niti? Denique non monimenta virum dilapsa videmus, querere proporro sibi cumque senescere credas non ruere avolsos silices a montibus altis, nec validas aevi vires perferre patique finiti? Neque enim caderent avolsa repente, ex infinito quae tempore pertolerassent omnia tormenta aetatis, privata fragore.

(De rerum natura, 5, 302-317).

3 "Chacune de ses métaphores a une histoire: elle renvoie indirectement à un mythe, à une cosmologie, à un traité de morale ou à l’Évangile. La pensée se fraye ainsi un paysage à travers des reflets et des alusions soigneusement disposés. Mais il faut encore se demander si certaines images et peut-être même le repertoire entier des figures mythologiques et des évocations rustiques n'a pas pour Ficin une valeur plus subtile et si l'on peut dire operatoire" (André Chastel, p. 47). 
ma d'un perfetto e vero amor l'amiamo.

Quel che conosce Dio, Dio a sé tira;

amando alla sua altezza c'innalziamo.

Nos versos do Magnífico o conhecimento de Deus torna-se o desejo supremo da alma e nele somente. Todas as demais formas da vida e do conhecimento devem ser entendidos como preparação mais ou menos consciente para voltar ao Criador. Esse é o destino irreversivel da alma. Tu ergo Deus noster, tu solos sitim hanc extingues ardentem. Aplacar-lhe a sede. Fonte das fontes.

Um encontro sublime entre 0 amador e a coisa amada. Um projeto de redenção onde coincidem o Bem e o Uno, a Causa eficiente e a Causa final, o Demiúrgo de Platãc e o Intelecto de Aristóteles. Tal a sobreposição de matizes da tradição platônica que alimenta a filosofia do retorno em Marsilio Ficino.

\section{III - Projetos de unidade}

Para compreendermos aquela teoria, é preciso recorrer às hipóstases de Plotino. Admirável desinterpretação do Parmênides. Negativa Transcendência do Uno. Radical dimensão meta-ôntica. O drama do retorno parte justamente destas questões.

Solidão do Primeiro Princípio. Eis o que constatamos - a respiração presa, a mente extasiada, o coração palpitante - desde as primeiras páginas de Plotino: o Uno real, o Uno total, aparece radicalmente separado do Universo, acima da essência e da vida, da parte e do todo. Não é qualidade ou quantidade. Não se move, nem descansa. Não possui forma ou figura. É absolutamente o Separado. Além do ser (epékeina óntos). Transcendência dele em tudo. Imanência de tudo nele. A multiplicidade do cosmo provém do não-múltiplo, e não pode existir a multiplicidade, sem a existência daquele. Assim é a árvore da vida. Onipotência absolutamente dona de si mesma. Tudo parte do Singular.

A superclaridade do Primeiro Princípio expande-se como plenitude que se comunica, autárquica e sem desejo, ao Filho. O pensamento - ato essencial do Intelecto - é plural e o seu índice metafísico é infinitamente menor se comparado ao Uno, mergulhado como se encontra na in-diferença. Eis a razão pela qual o Uno seria incapaz de pensar a si mesmo, pois, se assim o fizesse, deixaria de ser unidade originária, tornando-se sujeito e objeto. Conquanto deficiente e posterior, 0 Intelecto é o primeiro dos seres e, por um movimento de regresso (epistrophé) ao Pai, contempla o Uno, que não pode ser pensado senão como perene explicitação de si mesmo. A distância que os separa corresponde ao abismo do Infinito. Mesmo assim, o Filho é o ser mais próximo do Pai.

Ao deixar ser a diferença do Intelecto através da processão, o Uno nada perde de sua autarquia. Permanecendo, gera o Intelecto de si mesmo, tal como o fulgor dos raios solares. A inteligência primeira é um kósmos noetós que possui um aspecto ativo e subjetivo, o ato de pensar, e um aspecto passivo e objetivo, o conjunto das idéias. A vida do Intelecto é a luz primeira, que se acende e resplandece sobre si, iluminante e iluminada, puramente inteligivel, que se vê por si mesma e não tem necessidade de outra iluminação. Para Plotino, as idéias não representam o conteúdo do Intelecto, mas significam o próprio Intelecto. Cada idéia é ao mes- 
mo tempo intelecção e inteligência. Salvaguardar-se destarte a especial unidademúltipla do Filho.

Ao contemplar os inteligiveis, o Intelecto reverbera a imagem destes na Alma, comunicando-lhe o próprio ser. Dai porque a Alma é o verbo do Intelecto. Uma parte dela permanece no inteligivel, fora do cósmos; contemplando o Intelecto. A outra parte avança em direção dos seres sensiveis, aos quais dá vida. Se a primeira é comparada ao agricultor, a segunda é comparada à árvore. Aquela é transcendente. Esta, imanente. Sendo dupla a sua natureza, seria melhor para a Alma viver no inteligivel. Apesar disso, domina-a uma necessidade de participar do mundo sensivel. Eis a caracteristica que lhe permite criar o mundo com a memória dos inteligíveis. A Alma - diria Ficino num contexto maior - é o rosto da totalidade, o centro da natureza e a cópula do mundo.

A Alma do Todo envolve harmonicamente o corpo do Universo. Este participa tanto quanto possivel da beleza das idéias, pois a Alma produz contemplando os inteligiveis: as almas individuais, o Sol e as estrelas, os rios e os mares. $\mathrm{E}$ a beleza é o sinal de algo ainda mais profundo, o índice de uma imponderável nostalgia, a marca do regresso. A alma sonha com um plano de permanência e contemplação. O Belo é o prefácio do Bem. Eis o nosso destino. Plotino compreende o retorno a Deus como fuga do solitário ao Solitário (figué mónou prós mónon). Chega mesmo a lançar mão da metáfora de Ulisses:

"Fujamos pois à cara pátria. Mas como partir, como preparar esta fuga? Não certamente com os nossos pés, porque eles sempre nos levam de um lugar para outro da Terra. Nem é preciso aparelhar carruagens ou navios, mas abandonar todas estas coisas, e não lhes dirigir os nossos olhares, fechar os olhos corporais e despertar outros, que todos possuem, mas que poucos usam".

Um caminho interno e por mares metafísicos. Quando finalmente o solitário chegar ao Solitário, haverá a imanência da alma no Uno, união por presença, êxtase e abandono, esquecimento e arrebatamento. Com o retorno ao Uno fecha-se o círculo. O fim da conversão coincide com o princípio da processão.

\section{IV - Princípio e fim}

No cristianismo as questões da Trindade, da Criação e da Encarnação obrigam a repensar a identidade e a diferença. Passamos da emanação à criação. Do deus impessoal ao deus pessoal. Do não-desejo do Uno ao desejo do Pai. Da indiferença do Princípio à diferença do Verbo. Do indivíduo à pessoa.

Partindo de Agostinho e do Pseudo-Dionísio, podemos distinguir em Deus, em sua transcendente unidade, 0 mesmo e o outro. A identidade consiste no Deus imutável, sempre igual a si mesmo, infinito em sua perfeição, reunindo os atributos do Uno, do Intelecto e da Alma. Temos aqui a plenitude do ser. A diferença con-

siste na criação, transcendendo-se livremente a si mesmo, sem deixar de permanecer idêntico, uno e trino, sendo a diferença um momento interno da unidade divina. Afinal, garantida a transcendência de Deus, a pluralidade já não constitui uma diminuição a ser eliminada do Uno e a ser explicitada necessariamente fora dele. 
Ao aceitar semelhantes aspectos, Marsilio Ficino critica a teoria de uma processão circular e infinita, como se houvesse um perene permanecer, um perene proceder e um perene regressar. Parece-lhe absurdo um movimento sem fim: tudo seria igual a tudo, sem que a causa final pudesse atuar de modo transcendente. $O$ Uno seria apenas o suporte do processo circular. Além disso, Ficino também empresta às hipóstases um rosto e uma vontade. A solidão do Uno começa a sofrer uma grande mudança, pois a força que atrai o conhecido ao desconhecido,o significante ao significado, não pode repousar na clássica des-afeição do Uno. Se os homens amam o Primeiro Princípio, que acendeu em suas almas essa nostalgia, essa inquietude e essa paixão, também o Pai ama radicalmente e pessoalmente todos os homens. ${ }^{4}$ Ninguém mais se dissolve no seio da matéria universal ou na unidade de uma inteligência que é a forma da matéria humana. Trata-se de uma relação profunda e radicalmente pessoal. Deus agora tem face. Una e plural. Conhece os homens na diferença. E já não pode prescindir da face:

"Se amarmos os corpos, os espíritos, os anjos, na verdade não amaremos estes, mas Deus nestes. Por certo nos corpos amaremos a sombra de Deus; nos espíritos, a semelhança de Deus; nos anjos, a sua própria imagem. Assim, no presente, amaremos Deus em todas as coisas, a fim de que em Deus, em suma, amemos todas as coisas. Assim, pois, enquanto vivermos, a ele nos dirigiremos para ver não só Deus, mas todas as coisas em Deus, e amaremos não só ele próprio, mas ainda todas as coisas que estão nele mesmo. E quem quer que neste tempo com caridade se consagre a Deus, enfim, se salvará. Isto é, voltará à sua idéia, pela qual foi criado. Ai de novo, se algo the faltar será corrigido e se unirá perpetuamente à sua idéia. Então, o verdadeiro homem e a idéia do homem são a mesma coisa. Por isso, nenhum de nós na terra, separado de Deus, é um verdadeiro homem, visto que dele está separado pela idéia e pela forma. A ela nos levarão o divino amor e a piedade. Em todo o caso,aqui estamos repartidos e mutilados; então, amando, unidos à nossa idéia, nós nos tornaremos homens íntegros, posto que pareceremos ter primeiramente amado Deus nas coisas, para que depois amemos as coisas em Deus, e por isto pareceremos venerar as coisas em Deus para nele estimarmos sobretudo a nós mesmos, e, amando Deus, amamos a nós mesmos".

1 Aber diesen Streben des Bedingten zum Unbedingten entspricht auf der Seite des letzteren kein Gegenstreben. Das Überseiende und das über-Eine des Neuplatonismus steht auch über dem Leben (hýper tò zen). Die reine Objektivität des Absoluten steht als solche über der Sphäre des subjektiven Bewusstsein gefasst werden. Denn wie die Bestimmung des Strebens, so ist auch die des Erkennes von Absoluten femzuhalten. Alles Erkennen setzt die Beziehung auf ein anderes voraus, welche der reinen Autarkie des Absoluten seiner Geschlossenheit in sich selbxt widerstreiten würd. Ficinos Theorie der Liebe durchbricht diesen Gedankenkreis, sofern sie den Prozess dere Liebe als einen durchaus wechselseitigen Prozess fasst. Das Streben des Menschen zu Gott, das sich im Eros darstellt, wäre nicht möglich ohne ein Gegenstreben Gottes zum Menschen. Hier ist es der Grundgedanke der christlichen Mystik, der in Ficin lebendig wird, und der auch seinem Neuplatonismus eine neue Prägung gibt (Cassirer, Individuum und Kosmos, p. 139).

"Centrum mundi verum Deus est, ut in libre De Amore disseruimus, quia unus, simplex, stabilis est, et in omnibus, atque alia quaelibet omnino plura, composita, mobilia circa ipsum per naturalem ipsius appetitum perpetuo revolvuntur. Ita centrum Deus est omnium, quia sic est in omnibus, ut cuique rei interior sit quam ipsamet sibi. Est etiam circumferentia mundi quia extra cuncta existens, ita supereminet universa, ut cuiusque rei summum apicem dignitate excellat immensa. Item quanto est omnium (si dictu fas est) minimus quantitate, tanto virtute est maximus omnium. Ut est centrum quidem, est in omnibus, ut circumferentia vero, est extra omnia in omnibus, inquam, non inclusus, quia est et circumferentia. Extra omnia quoque non exclusus, quia est et centrum. Quid ergo Deus est? Ut ita dixerim circulus spiritualis, cuius centrum est ubique, circumferentiam nusquam" (Theologia Platonica, 18, 3). 
Como bem observou Kristeller, a vontade é o verdadeiro princípio que põe a alma em movimento e a conduz até o seu fim. $O$ intelecto, considerado superior até quando a mente humana estava um pouco acima dos objetos, revela-se inferior quando o objeto ultrapassa a capacidade do pensamento humano. Só o amor propicia a união: Propius unimur Deo per amatorium gaudium. O intelecto permanece fechado em si mesmo, enquanto que a vontade busca o objeto. $\mathrm{O}$ amor e a beleza coincidem aqui. Fons totius pulchritudinis deus est. Fons totius amonis est deus. E a idéia do homem e a sua plenitude também se identificam. O sujeito continua sendo o rizoma dessa metafísica. ${ }^{6}$ Pois a diferença torna-se um espelho, onde 0 amador se reflete na coisa amada e a coisa amada se reflete no amador. Que mais pode refletir o espelho senão a própria face?

\section{Referências bibliográficas}

ALLEN, Michel JB. The Platonism of Marsilio Ficino. California, University of California Press, 1984.

ANICCHIN, Giuseppe. L'Umanesimo e il Problema della Salvezza in Marsilio Ficino. Milano, Vitae Pensiero, 1937.

BAKTIN, Leonid. I'Idea di Individualità nel Rinascimento Italiano. Bari, Laterza, 1992.

BEIERWALTES, Wemer. Marsilio Ficinos Theorie des Schönen im Kontext des Platonismus. Heidelberg, Carl Winter Universitätsverlag, 1980.

BURCKHARDT, Jacob. A Civilização da Renascença Italiana. Lisboa, Presença, s/d.

CARUS, Tito Lucretius. La Natura (ed. bilingüe). Milano, Rizzoli, 1988, 7a. edição.

CASSIRER, Ernst. Individuum und Kosmos in der Philosophie der Renaissance. Leipzig/ Berlin, Teubner, 1927.

CASTELLI, Patrizia et alii. Il Lume del Sole. Marsilio Ficino, Medico dell'Anima. Firenze, Opus Libri, 1984.

CERULLI, Enrico et alii. L'Averroismo in Italia. Roma, Accademia Nazionale dei Lincei, 1979.

CHASTEL, André. Marsile Ficin et l'Art. Genève, Lille CNRS, 1954.

CORNFORD, F. M. Principium Sapientiae. Lisboa, Calouste, 1989, 3a. edição.

DRESS, Walter. Die Mystic des Marsilio Ficino. Berlin und Leipzig, Walter de Gruter e Co., 1929.

EISENBICHLER, Konrad e PUGLIESE, Olga. Ficino and Renaissance Platonism. Toronto, University of Toronto/ Dovehouse, 1986.

FICINO, Marsilio. El Libro dell'Amore (a cura di Sandra Niccoli). Firenze, Istituto Nazionale di Studi del Rinascimento/Leo Olschki, 1987.

—. De Vita (a cura di Albano Biondi e Giuliano Pisano). Pordenone, Edizioni dell'Immagine, 1991.

— Über die Liebe oder Platons Gastmahl (übersetzt von Karl Paul Hasse herausgegeben und eingeleitet von Paul Richard Blum). Hamburg, Felix Meiner Verlag, 1984.

GARFAGNINI, Giancarlo. Marsilio Ficino e il Ritorno di Platone. Firenze, Olschki, 1986

GARIN, Eugenio. O Zodíaco da Vida. Lisboa, Estampa, 1988.

- Idade Média e Renascimento. Lisboa, Estampa, 1989.

GOMBRICH, E. H. Norma e Forma. São Paulo, Martins Fontes, 1990.

HÖNIGSWALD, Richard. Denker der Italienischen Renaissance, Gestalten und Probleme. Basel, Haus zum Falken Veerlag, 1938.

JÄGER, Michael. Die Theorie des Schönen in der Italienischen Renaissance. Köln, Dumont Buchverlag, 1990.

KLIBANSKY, Raymond, PANOFSKY, Erwin e SAXL, Fritz. Satum und Melancholie. Frankfurt am Maim, 1990.

KLUNSTEIN, Ilaná. Marsilio Ficino et la Théologie Ancienne. Firenze, Leo Olschki, 1987.

B Cf. o estudo exemplar de Werner Beierwaites, op. cit., p. 40-48. 
KRISTELLER, O. P. Die Philosophie des Marsilio Ficino. Frankfuirt am Main, Vittorio Klostermann Verlag, 1972.

. Acht Philosophen der Italienischen Renaissance. Weinheim, Acta Humaniora, 1986.

MAHNKE, Dietrich. Unendliche Sphäre und Allmittelpunkt. Stuttgart, Bad Cannstadt, 1966. 2a. edição.

MICHAEL, Jäger. Die Theorie des Schönen in der Italienischen Renaissance. Köln, Dumont Verlag, 1990.

MONDOLFO, Rodolfo. O Pensamento Antigo. São Paulo, Mestre Jou, 1971.

OEHLING, Ute. Die Philosophische Begründung der Kunst bei Ficino. Stuttgart, Teubner, 1992.

POMPONAZZI, Pietro. De Immortalitate Animae (a cura di Giovanni Gentile). Messina-Roma, G. Principato, s/d.

— Abhandlung über die Unsterblichkeit der Seele (herausgegeben von Burkhard Moysich). Hamburg, Felix Meiner Verlag, 1990.

- Corsi Inediti dell'Insegamento Padovano. Padova, Antenore, 1966.

ROBB, Nesca A. Neoplatonism of the Italian Renaissance. London, George Allen e Unwin, 1935.

SATTTA, Giuseppe. II Pensiero Italiano nell'Umanesimo e nel Rinascimento. Bologna, Cesare Zuffi, 1949.

WALKER, D. P. Spiritual and Demonic Magic from Ficino to Campanella. London, Warburg Institute, University of London, 1958.

YATES, Frances. Giordano Bruno. São Paulo, Cultrix, 1995.

ZINTZEN, Clemens (herausgegeben von). Die Philosophie des Neuplatonismus. Darmstadt, Wissenchaftliche Buchgesellschaft, 1977. 